\title{
Low Pension Benefits- The Overarching Issue of Agitations by Doctors and Nurses in Greater Accra Region, Ghana 2005-2015
}

\author{
Anthony Kwame Apedzi*1, Albert Ahenkan² and Comfort Michelle Apedzi ${ }^{3}$ \\ ${ }^{1}$ Ministry of Health, Ghana \\ ${ }^{2}$ University of Ghana Business School, Ghana
}

${ }^{3}$ Christian Health Association of Ghana

*Corresponding author: Anthony Kwame Apedzi, Ministry of Health, Ghana

\section{ARTICLE INFO}

Received: 㐩 February 15, 2019

Published: 㓞 February 26, 2019

Citation: Anthony Kwame A, Albert A, Comfort Michelle A. Low Pension Benefits- The Overarching Issue of Agitations by Doctors and Nurses in Greater Accra Region, Ghana 2005-2015. Biomed J Sci \& Tech Res 15(2)-2019. BJSTR. MS.ID.002668.

Abbreviations: HSS: Health the Sector Salary Structure; SSPP: Single Spine Salary Pay Policy; FGDs: Focus Group Discussions; GUSS: Ghana Universal Salary Structure; SSNIT: Social Security and National Insurance Trust; NRCD: National Redemption Council Decree; PCP: Presidential Commission on Pensions; TUC: Trade Union Congress; HSWU: Health Service Workers Union; GMA: Ghana Medical Association; GRNMA: Ghana Registered Nurses and Midwives Association; GHOSPA: Government and Hospital Pharmacist Association; TPF: Temporary Pension Fund

\section{ABSTRACT}

This research assessed pension factor in doctors and nurses' agitations and the role of the new pension scheme in addressing that challenges in Ghana. Due to the deficiencies in the old pension schemes which led to the call for pension reforms and better motivational packages, the introduction of the new pension scheme is therefore expected to induce employees' satisfaction and motivate workers in general. The aim of the research was to investigate the underlining causes of strikes actions embarked upon by public sector doctors and nurses in the Greater Accra Region between from 2005 to 2015. That period saw several agitations by health workers which made government established two pay policies, namely: The Health; the Sector Salary Structure (HSS) and the Single Spine Salary Pay Policy (SSPP). This research adds to scanty published literature and other sources, which ascertained the actual causes of these health workers agitations and the role of the new pension scheme in Ghana. The investigators used in-depth interviews and a mixed method made up of quantitative and focus group discussions (FGDs). The number of professional nurses and doctors in Greater Accra Region, according to the Ministry of Health, is 5426 (2015).

Ten percent (10\%) population size was used in the study. A total of 557 questionnaires were administered within four weeks in five public health facilities in Greater Accra Region, namely: Korle bu Teaching Hospital (tertiary healthcare facility), Ridge and Tema General hospitals (secondary healthcare facilities), and LEKMA and Mamprobi Hospitals (primary healthcare facilities). The research revealed that, one of the major causes of health workers agitation is the fear of insecurity after retirement having witness some of their colleagues struggled for survival after they retired from active service. Again it was revealed that majority of the doctors and nurses wish to determine the rate of pension benefits payable to them after retirement. They want to work towards the payment of specific higher premium, to enable them to receive specific higher amount after retirement. The research recommends that more education should be done on the new Pension Scheme for public sector health workers.

\section{Introduction}

The issues concerning pensions, for public health sector workers in Ghana have attracted much attention, as they mostly become the focus for salary agitation. Pension has been the focus, as salary for public health workers have undergone several changes

and reforms, in a bid to pay salaries that is commensurate to performance and the demand of workers, as stipulated by the Fair Wages and Salary Commission (2014). From the Ghana Universal Salary Structure (GUSS), introduced in 1999 to the current Single 
Spine Pay Policy (SSPP), which was introduced in 2010, pension issues, particularly among doctors and nurses in the public health sector, have been prominent. An effective reform of the pension system in Ghana, was required to respond to the frequent agitations by the doctors and nurses, over pension issues.

There have been various pension reforms in Ghana which dates back as early as the year 1950 (Gockel \& Kumado 2003). Before the establishment of a formal pension scheme as a means of providing social security to public sector workers in Ghana, the extended family system was the main source of social protection for most Ghanaian public sector workers after retirement. The extended family was the institution in Ghanaian community that provided social and economic support to various family members at appropriate times of need. It was, traditionally, a source of support when members became old and threatened by economic deprivation, disability and social isolation (Kumado \& Gockel 2003).

This uncertainty about pension has also raised concerns as to how the average worker especially in the health sector is motivated and remunerated. Across the globe, the desire to increase productivity has been a major concern for all organizations both in the public and private sectors, great and small alike. Most organizations globally especially in the public health sector usually adopt measures that focus on sophisticated technology, equipment, capital and other materials, more often than paying maximum attention to the 'human side of the enterprise', that is the workforce [1]. Health workers occupy a central position in any health care facility in a country and as such their security after their working years, needs to be assured to allay their fears about their future.

Health workers heal and care for people, relieve them of their pain and suffering and prevent diseases (WHO, 2006). The World Health Organization again recognize health workers as the ultimate resource in health because they manage and synchronize all other health resources, including financing, technology, information and infrastructure" (WHO 2004) Therefore, for them to work effectively, they must be motivated and supported with attractive pension packages that will help to reduce, if not totally eradicate health worker agitations. In addition, lack of motivation and good pension policies partly explain why health workers in most developing countries like Ghana, migrate to western countries. This has resulted in the reformation of various salary structures and pension policies in the bid to motivate health workers for higher productivity and retention (WHO 2004).

\section{Literature Review}

\section{The Concept of Social Protection}

There has always been a need for social protection universally. Before the emergence of well-structured or institutionalized social security schemes, the family was the main source of social protection in the pre-colonial era. However the advent of colonial rule or colonialism was one of the major factors responsible for the occurrence of institutionalized schemes in many sub Saharan countries including Ghana. Additionally, the prevalence of other issues pertaining to poverty, health and conflicts caused the role of the family to decline. These issues eventually raised the urgency and popularity of social protection systems which resulted in the introduction of pension schemes [2]. The review looks at the concept of pensions, the new 3 tier pension scheme, benefits of the new scheme and problems of new pension scheme.

\section{Pensions}

A pension scheme refers to a long term investment vehicle whose principal objective is to provide decent and reliable income upon retirement [3]. The development of the public pension systems in Ghana has its origins set in early colonial systems. In the year 1950, the British authorities present in the Gold Coast (now Ghana) created a Pensions Ordinance to replace and unify the Pension (for European Officers) Ordinance and (for Non-European Officers) Ordinance into a single non-discriminatory pension scheme that gave equal benefits to both local and expatriate workers in the country at that time. The new scheme which came to be known as CAP 30 (a name derived from chapter 30 of the Pension Ordinance of 1946) was a non-contributory scheme designed as a reward for civil servants and public service workers who had worked for a period of at least ten years and had attained the voluntary retirement age of forty five or the compulsory age of fifty years (Gockel \& Kumado 2003).

CAP 30 Pension Scheme: According to the National Pensions Regulatory Authority (NPRA), the Chapter 30 of the 1950 British Colonial Ordinance (Pension Ordinance No. 42), also known as CAP 30 was a non-contributory pension scheme. It rewarded civil and public servants when they retire from active service. A handsome lump sum was paid to the retirees as well as a monthly allowance. But among others, it was realized that CAP 30 did no cover workers in informal sector who are constitute about $85 \%$ of workforce in Ghana (NPRA, 2010).

Social Security and National Insurance Trust Scheme: The Social Security and National Insurance Trust (SSNIT) was established in 1972 by the National Redemption Council Decree (NRCD) 127, as a contributory pension scheme (SSNIT, 2015). It was a mandatory and universal pension scheme. According to the formula for calculating pension benefits, the employer contributed $12.5 \%$ of employee's base pay, while the employee also contributed $5 \%$ of his/her base pay towards pension. It covered both public and private sector employees.

\section{Pension Reforms}

In July 2004, President John Agyekum Kufuor established a Presidential Commission on Pensions (PCP) to address the concerns of Ghanaian workers with regards to some discrepancies in the benefit package for retirees under both the CAP 30 and SSNIT pension schemes. (SSNIT, 2014). The commission headed by Mr. T.A Bediako was tasked with the responsibility of creating a uniform pension scheme that would ensure retirement income security 
for all Ghanaian workers. The recommendations brought forth by the commission were for the creation of a new contributory three tier pension scheme, consisting of two mandatory schemes and a voluntary scheme. They also recommended that the CAP 30 scheme be abolish since it was not contributory, that is, employees do not contribute monthly premium to it. CAP 30 also became expensive to run as the number of people in the civil and public services increases. Again the committee recommended that the SSNIT scheme should be restructured by revamping its management and administrative structures (SSNIT, 2014). To honor the commission's recommendations, a National Pensions Regulatory Board was established to regulate both public and private pension schemes in the country. Additionally, a National Pensions Act, Act 766 of 2008, was established to cater for the new contributory three tier pension scheme (ibid).

The New 3 Tier Pension Scheme: The new 3 Tier Pension Scheme was established with the following characteristics:

First Tier: The first tier is a basic national social security scheme that is managed by Social Security and National Insurance Trust. It is mandatory for all employees in both private and public sectors but optional for the self-employed and informal sector workers [2].

Second Tier: The second tier is also a mandatory scheme for all employees. However the main difference between this tier and first is that, it is privately managed by registered Pension Fund Managers and Custodians who are regulated by approved trustees licensed by the National Pensions and Regulatory Authority. Pension fund managers as per the National Pensions Act of 2008, are responsible for investing pension funds and assets in investments achieving the best return. Custodians are also charged with receiving contributions remitted by employers on behalf of trustees [4].

Third Tier: The third tier is a voluntary scheme that enables individuals to freely open provident funds and personal pension scheme which are managed by Pension Fund Managers. This tier is supported by tax benefit incentives to provide additional funds for workers who want to make contributions to enhance their pension benefits. It also allows individual to make additions or top-ups that are $16.5 \%$ of their gross salary. This scheme is particularly designed to meet the contribution needs of workers in the informal sector of Ghana [4].

\section{Benefits of the New Scheme}

One of the underlying features of the new pension scheme is the fact that, it is drafted with the socio cultural environment of Ghanaians at heart. For instance the commission set up to create the new scheme, were cognizant of the fact that, in Ghana, the needs of individuals rather increase upon retirement due to demands placed on him from traditional customs such as family engagements and other social responsibilities. In addition to be an entirely new scheme, the new 3 tier scheme was in many ways better than the pre-existing CAP 30 and SSNIT pension schemes. Some of these distinguishing features outlined by SSNIT (2014), which double as benefits of the new scheme include the following;

a) An improvement in the entry/maximum age at which a person may join the social security scheme. The numbers of years for contribution to enable one to qualify for the pension benefits have been reduced from 20 years to 15 years while the new minimum age is 45 years.

b) An improvement in the second tier lump sum benefits or returns that are higher than the benefits under the CAP 30 scheme and far higher than that of the SSNIT scheme. This is probably due to fact that, the second tier is privately managed and as such will be invested in high yielding investments.

c) An opportunity to use future lump sum pension benefits to secure mortgages. This gives a worker the opportunity to own his or her own house before retirement by using their pension benefits as collateral.

d) An opportunity for workers to have better control over their pension benefits under the second and third tier schemes which are both managed privately.

e) An opportunity for funds to grow since no arbitrary withdrawals is allowed.

\section{Problems of New Pension Scheme}

Although on paper, the new three tier pension scheme is the perfect solution to the discrepancies existing in the SSNIT specifically, with its dwindling investment returns and improving access to informal sectors. It has encountered its share of scrutiny and difficulties prior to its implementation. According to Okine (2012), the National Pension Regulatory Authority (NPRA), in 2010 set up a Temporary Pension Fund (TPF) to provisionally administer Tier 2 contributions pending the licensing of Trustees. As a result, employees including health workers have been paying $5 \%$ of their salaries to the TPF. According to the research, there have been allegations that the Acting Chief Executive Officer of NPRA has been making unapproved withdrawals from the accounts of hard working Ghanaian employees. Additionally, a third party service provider tasked with the duty of managing and providing data concerning the use of tier 2 contributions, has no record of information concerning the use of tier 2 contributions since the establishment of the TPF in 2010. There have also been issues concerning NPRA's delays in the registration and licensing of trustees, pension fund managers as well as custodians leading to the implementation of the new scheme [5-11].

Since the passage of the New Pensions Act in 2008, Act 766, the NPRA has failed to fully implement the new three tier pension scheme as a fully operational scheme in Ghana. It has taken almost four years just to register and license its trustees, fund managers and custodians which has put a stump to its implementation. Although, it has tried to speed up the process by initiating the TPF, it has failed miserably amidst allegations of embezzlement of 
employee's contributions and its inability to account for what the contributions into the TPF have been used for since 2010. If the NPRA continues in this stead, it would most likely raise the risk of retired workers not having access to their lump sum benefits. In fact, people who have retired since 2011 but have made their $5 \%$ tier 2 contributions still cannot access their lump sum benefits based on their contributions into the TPF since January 2010. There is also concern of whether the contributions paid into the TPF have even been invested because of the NPRA's failure to show records as proof of the fund's availability. Most companies that were established in preparedness for the implementation of the scheme are running out of funds they heavily invested in the business [5].

\section{The Objective of the Research}

The main aim of the study was to assess the pension factor in doctors and nurse's agitation, and the role of the new pension scheme in addressing challenges of pensions in Ghana. The study has enabled readers understand pensions system in Ghana, motivation and employee satisfaction among health workers in public sector in Ghana especially doctors and nurses in the Greater Accra Region of Ghana. Finally, other stakeholders, such as the Ministry of Health and its agencies would also find the study significant, to inform their decision making especially on pensions.

\section{Research Question}

What are the underlining causes of strikes by public sector doctors and nurses in the Greater Accra Region from 2005 to 2015?

\section{Methodology}

The study concentrated on the leadership of the trade unions in the healthcare delivery sector in Ghana, as key informants. This is because the cardinal principle of the trade unions is to see to the welfare of members. According to the Trade Union Congress (TUC), there are four trade unions in the health service as at July 2016. They are; the Health Service Workers Union (HSWU), the Ghana Medical Association (GMA), Ghana Registered Nurses and Midwives Association (GRNMA) and the Government and Hospital Pharmacist Association (GHOSPA). The study looked at the trade union of the doctors and midwives as the focus of the study. According to the Ministry of Health (2015), the population of doctors and nurses in the Greater Accra Region, is five thousand, four hundred and twenty-six $(5,426)$. A sample size of five hundred and fifty-one (551) respondents, which represents more than $10 \%$ of this population of doctors and professional nurses, was chosen from public health institutions in the Greater Accra for this study.

Due to the large population size and resource constraints, the study adopted purposive and random sampling technique for doctors and nurses. Purposive sampling technique was employed to the doctors for the study. Random sampling was also used to select the nurses. The $10 \%$ of population size, according to Mason (1997), can be used to make generalization. The sample size was determined using the formula is the population and is the sample.

$$
\frac{\sigma}{n}=\frac{5426}{10}=542.6
$$

A trained research assistant distributed structured questionnaires to five hundred and fifty-seven (557) doctors and nurses who are who work in the public sector in the Greater Accra Region. The institutions were: Korle bu Teaching Hospital (tertiary healthcare facility), Ridge and Tema General Hospitals (secondary healthcare facilities), and LEKMA and Mamprobi Hospitals (primary healthcare facilities). The researchers chose this approach because findings from both key informant interviews and the structured questionnaires, complemented each other which enable the researchers to adequately achieve the research objectives. The outcome of the quantitative methods assisted in generalizing about the study population, while that of in-depth interview elicited in-depth explanations on the issue of pension and agitations.

Due to the large population size and resource constraints, the study adopted purposive and random sampling technique for the doctors and nurses who are members of trade unions in the health sector in Greater Accra. Purposive sampling technique was employed to select medical doctors and dentists from the Ghana Medical Association (GMA). Random sampling was also used to select the nurses from the Ghana Registered Nurses Association (GRNA). Members of the GRNA constitute the larger number in the health care delivery industry in Ghana (MOH 2016). The purposive and random methods used, according to Saunders and Philip (2009) will give respondents equal chances of been selected. The data obtained from respondents was analysed using the Statistical Package for the Social Sciences (SPSS) software programme version 16. Responses to interviewees were recorded, classified and coded for the necessary analysis (Table 1 ).

Table 1: The National Labour Commission has a data on strike actions undertaken by the public health sector including the doctors and nurses. The following table shows some of the reasons for strike.

\begin{tabular}{|c|c|c|c|c|c|c|}
\hline Years & Unfair Termination & Unpaid Salaries & Retirement and ESBs & Compensation & Redundancy & Medicals \\
\hline 2015 & 212 & 49 & 9 & 21 & 2 & 62 \\
\hline 2014 & 151 & 34 & 33 & 22 & 74 & 3 \\
\hline 2013 & 196 & 18 & 5 & 26 & 74 & 1 \\
\hline 2012 & 190 & 12 & 6 & 27 & 31 & 3 \\
\hline
\end{tabular}

\section{National Labour Commission 2016}

The National Labour Commission and the Ministry of Health could not provide adequate data on the number of strikes embark upon by the doctors and nurses within the period under review (2005-2015). 


\section{Period for the Research}

The research was conducted from January 2015 to September 2016.

\section{Findings}

Out of the five hundred and fifty-seven (557) questionnaires administered, five hundred and fifty-one (551) were returned.
The other six (5) were not returned as the respondents seems to be very busy and changing shifts. The major questions solicited in the research is highlighted in Table 2. On a 5-point likert scale, the mean and standard deviation of the responses given were computed. These responses were collated from health workers of the two major trade unions in the country. These were Ghana Medical Association (GMA) and the Ghana Registered Nurses and Midwives Association (GRNMA).

Table 2.

\begin{tabular}{|c|c|c|}
\hline Pension & Mean & Standard deviation \\
\hline 1. I will pay for a higher premium to enable me to receive the monthly payment & 4.71 & 0.623 \\
\hline $\begin{array}{c}\text { 2. I am ready to top up the statutory pension deduction at the end of every month to enable me to receive the } \\
\text { payment I desire as monthly benefit }\end{array}$ & 4.45 & 0.363 \\
\hline 3. I have faith in the current 3 tier pension & 3.98 & 0.724 \\
\hline Strike & & \\
\hline 4. I am aware that as an essential service provider, I do not have to go on strike & 4.62 & 0.352 \\
\hline as it may affect human life. & 4.87 & 0.812 \\
\hline 5. I go on strike because of delayed salaries. & 4.77 & 0.78 \\
\hline 6. I go on strike for salary increases & 4.33 & 0.524 \\
\hline 7. I go on strike because of decisions that might adversely affect my retirement & 4.25 & 0.475 \\
\hline 8. Strikes help me to achieve my aim & \\
\hline
\end{tabular}

Source: Fieldwork, 2016.

\section{Discussion}

With regards to the issue concerning whether health workers are willing to pay for a higher premium to enable me to receive the specific monthly payment, a high mean of 4.71 and a standard deviation of 0.623 were produced. This outcome suggests that the health workers are willing to pay more premiums in order to increase the monthly payments made to them upon retirement. Consequently, a mean and standard deviation of 4.45 and 0.363 , respectively, were derived for the statement which bothered on the readiness to top up the statutory pension deduction at the end of every month to enable them to receive the payment they desire as monthly benefit. This affirms the earlier view that the health workers agree on the need to pay more pension premiums. The respondents agreed that they have faith in the current 3 tier pension scheme. However, the recorded relatively low mean value and its standard deviation is 3.98 and 0.724 respectively.

Moreover, the views of the respondents were sought on why they resort to strike actions and the impact they hope to make for such actions. A mean of 4.87 and standard deviation of 0.812 revealed that the respondents agree that delayed salaries are the reasons why they embark on strike actions. Similarly, they agreed that they go on strike to agitate for increment in their salaries (mean=4.77, standard deviation=0.78). They also agreed that strike actions become necessary when decisions concerning their retirement are not in their favor (mean=4.33, standard deviation=0.524). In addition, it is their conviction that strike actions help them to achieve their aim (mean=4.25, standard deviation=0.475). On the contrary, the respondents agreed that as an essential health provider, they do not have to go on strike since it may affect human life (mean=4.62, standard deviation=0.352).

The study revealed that the main causes of doctors and nurses' agitations are poor remuneration and unattractive conditions of service which according to them, threatens their welfare when they go on retirement. The study also found that, the relaxed attitude of Government towards pension issues and motivational packages, give them no choice but to express their dissatisfaction through the consistent industrial strikes. Again, one major problem that acts as a setback to the proper management and effective role of the new three tier pension scheme is the fact that, majority of the health workers are not aware or do not understand what the new pension scheme is about. The various stakeholders interviewed therefore have high expectations of the new pension scheme. For instance, it is expected that the newly established pension scheme would have an all-round benefit for the country, where public sector health workers can confidently go for mortgage properties using their pension contribution as collateral.

In corresponding terms, $72 \%$ did not like the rate of premium paid currently under the SSNIT pension scheme. They say it is small and their pension benefit will also be small. Hence, 22\% said they are willing to pay any amount of insurance premium to enable them to receive not less than an equivalent of 600 dollars every month after retirement. While $36 \%$ also wish to pay any amount of 
insurance premium that will guarantee a monthly payment of 500 dollars equivalent. Again, $42 \%$ wish they could get an equivalent

\section{References}

1. Abubakr M, Nawal A (2009) Surviving Through the Global Downturn: Employee Motivation and Performance in Healthcare Industry. The Open Business Journal 2: 86-942.

2. Kpessa M (2011) The politics of retirement income security policy in Ghana: Historical trajectories and transformative capabilities. African Journal of Political Science and International Relations 5: 92-102.

3. Britam (2012) What is a Pension Scheme and how does it work?

4. (2008) National Pensions Act, (ACT 766).

5. Okine B (2012) New Pension Scheme under threat. Graphic Business. $27^{\text {th }}$ September. p. 1.

\section{ISSN: 2574-1241}

DOI: 10.26717/BJSTR.2019.15.002668

Anthony Kwame Apedzi. Biomed J Sci \& Tech Res

(c) (i) This work is licensed under Creative

Submission Link: https://biomedres.us/submit-manuscript.php
6. Adams GR, Schvaneveldt J D (1985) Understanding Research Methods. New York: Longman, USA.

7. Kpessa M (2011) A comparative analysis of pension reforms and challenges in Ghana and Nigeria. International Social Security Review 64: 92-104.

8. Kumado Kofi, Gockel Fritz (2003) A study on social security.

9. (2004) Ministry of Health. Joint Learning Initiative, Ghana 2004: 26.

10. (2002) Ministry of Health. Human Resource Policies and Strategies for Health Sector 2002-2006, Ghana.

11. Saunders MNK, Philip L, Thornhill A (2009) Research Methods for Business Students. $5^{\text {th }}$ edition, Pearson Publication, London, England, UK.

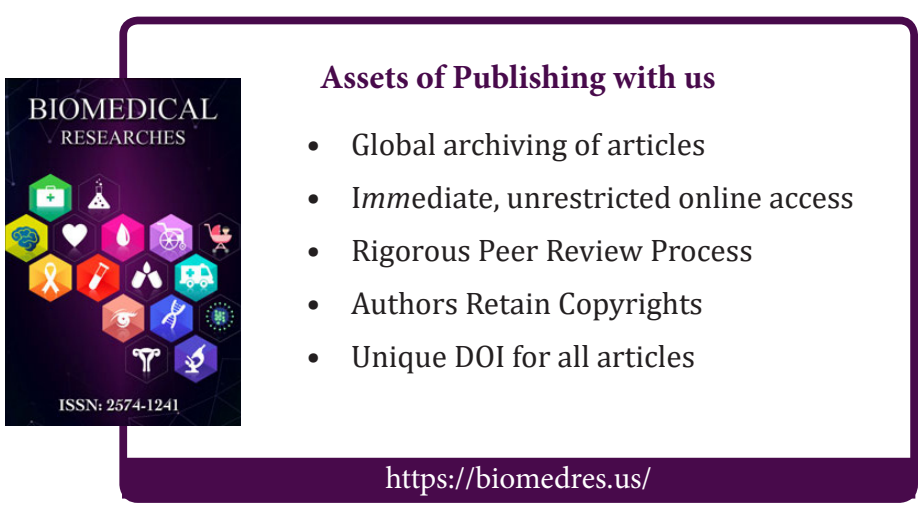

